\title{
O PROCESSO DE FORMULAÇÃO E IMPLEMENTAÇÃO DE PLANEJAMENTO ESTRATÉGICO EM INSTITUIÇÕES DO SETOR PÚBLICO
}

\author{
THE PROCESS OF FORMULATING AND IMPLEMENTING \\ STRATEGIC PLANNING IN PUBLIC SECTOR INSTITUTIONS
}

Recebido 04/10/2011

Aceito 20/11/2011

Flávia de Araújo e Silva e Carlos Alberto Gonçalves

\section{RESUMO}

Este trabalho discorre sobre alguns modelos adotados na formulação e implementação do Planejamento Estratégico vis-à-vis apoiar a gestão de estratégias propostas como deliberadas em instituições públicas. Foram feitas pesquisas bibliográficas sobre teorias da estratégia e seus processos de formação e elaboração do documento para ser seguido como "plano estratégico". As unidades de análise foram os tribunais de contas dos estados e municípios do Brasil. Adotaram-se métodos combinados de pesquisa bibliográfica, consultas aos planos estratégicos de algumas instituições públicas, pesquisas qualitativa e quantitativa por meio de entrevistas e aplicação de questionário como survey. No âmbito das instituições públicas, foram identificados os modelos preferidos para formulação e implementação do plano estratégico, a saber: Método Grumbach, Balanced Scorecard (BSC) e Gerenciamento pelas Diretrizes. Os resultados apontam a existência de fortes crenças das equipes quanto à efetividade da prática regular do "Planejamento Estratégico" no sentido de promoverem melhor alinhamento estratégico geral. Concluiu-se também que as instituições pesquisadas ainda estão em fase de aquisição de aprendizagem dessa instrumentalização, principalmente no que tange à execução das ações propostas no planejamento.

Palavras-chave: Planejamento Estratégico. Setor público. Tribunais de contas. 


\begin{abstract}
This paper aim to discuss some models for formulation and processing of the strategic planning vis-àvis to support management of main deliberate strategies in public institutions. We researched bibliographies of theories about practices and processes of strategy formation until the development of the document to be followed as "Strategic Plan". The units of analysis are the Audit Courts of the States and Municipalities of Brazil. It was adopted combined methods of literature review, consultations to the strategic plans of some public institutions, qualitative and quantitative research through interviews and survey. Within public institutions it was identified the favorite models used for the formulation and implementation of organizational strategic plan namely: Grumbach Method, Balanced Scorecard (BSC) and Management by Policy. The research results indicate the existence of strong team's beliefs in the effectiveness of the "strategic planning" as a regular practice in a way that provide better overall strategic alignment. It was concluded also that the institutions researched are still in a step of acquiring apprenticeship for this instrumentalization, mainly in respect to put into action the planned actions.
\end{abstract}

Keywords: Strategic Planning. Public sector. Audit courts.

\title{
1 INTRODUÇÃO
}

A formulação e implementação de estratégias nas organizações e sua documentação são um tema recorrente no meio organizacional, pelas crenças de que o futuro pode ser alcançado a partir do presente (experiências de sucesso reforçam essa cultura). Os decisores acreditam que os cenários podem ser delineados ex ante as definições de objetivos futuros por equipes que produzem comprometimento, é melhor planejar, para evitar surpresas, que não planejar, promove-se alinhamento estratégico entre o desejado pela governança e os resultados alcançados. Assim, o Planejamento Estratégico (PE) tem encontrado praticantes tanto no setor privado quanto no público, como instrumento de redução de incertezas e norteador dos passos futuros dos dirigentes no sentido de obtenção de resultados superiores.

Toda organização tem uma estratégia, seja emergente ou deliberada. As estratégias emergentes surgem para fazer com que as deliberadas, na medida do possível, se mantenham com um sentido existencial e pragmático, orientadas para os resultados. As deliberadas são as que justificam o PE e são os arquétipos do sensemaking da estratégia. Na coleção de estratégias possíveis, deliberadas, emergentes e a não decisão completam o conjunto, ou seja, a decisão estratégica não é apenas o que a organização pretende fazer, mas também o que a organização decide não fazer.

A concepção de Planejamento Estratégico surgiu da necessidade das organizações se programarem, evitando surpresas onerosas, frente à velocidade das mudanças que ocorrem no ambiente. Foram elaborados diversos modelos pelos estudiosos do tema (alguns serão apresentados neste trabalho), e sua aplicação nas empresas privadas se tornou "quase compulsória" em meados do século XX. Certo tempo depois, a tendência se alastrou para o setor público. Entretanto, existe carência de estudos sobre o processo de formação do Planejamento Estratégico em instituições públicas (GIACOBBO, 1997). Portanto, a escolha da temática Planejamento Estratégico no setor público justifica-se pela necessidade de aprofundar os estudos nessa área, que ainda são escassos quando comparados ao setor privado. As questões ligadas à concorrência e às vantagens competitivas deixam, então, de ser o foco, passando a ser a efetividade dos serviços prestados à sociedade.

Nesse sentido, este trabalho propõe abordar a seguinte questão geral de pesquisa: como ocorrem a formulação e implementação do Planejamento Estratégico em instituições do setor 
público - Tribunais de Contas do Brasil? A pesquisa terá como foco os seguintes objetivos específicos: discorrer sobre os processos de formulação e implementação do planejamento estratégico nas unidades de análise, levantar as crenças sobre sua efetividade e pesquisar quais são as metodologias comumente utilizadas em setor de baixa competitividade, o setor público.

Primeiramente, será feito um levantamento teórico sobre estratégia e as diferentes correntes de pensamento sobre a formação de estratégias. Logo após, passa-se para o levantamento teórico sobre Planejamento Estratégico e suas características no setor público. São apresentados, então, os métodos geralmente utilizados para formular e implementar estratégias no setor estudado: Método Grumbach, Balanced Scorecard e Gerenciamento pelas Diretrizes. Por fim, são apresentados a metodologia de pesquisa, explicando seu caráter quali e quantitativo, os resultados dessa pesquisa empírica e as considerações finais.

\section{CONTEXTUALIZAÇÃO SOBRE ESTRATÉGIA}

As origens da estratégia vêm de tempos remotos: o planejamento de guerra em operações militares, baseadas nos escritos de Sun Tzu por volta de 500 a.C. A discussão sobre o tema foi bastante destacada por volta de 1960, com autores como Igor Ansoff, e consagrada nas décadas de 1980-1990 do século XX, por autores como Henry Mintzberg e Michael Porter.

Mintzberg et al. (2003) mencionam que não existe um conceito único e universalmente aceito para estratégia. Os autores propõem a definição de estratégia em $5 \mathrm{P}^{\prime}$ s, sendo estratégia como plano, pois são formalmente criadas antes de serem implementadas e se desenvolvem propositalmente; como pretexto, ou seja, uma manobra para se atingir um determinado objetivo não explicitado; como padrão, que é o comportamento resultante das ações; como posição, relação entre o ambiente interno e o ambiente em que a organização está inserida; e como perspectiva, que remete à cultura da organização, à sua forma de agir e se relacionar com os stakeholders. Dentre esses conceitos, o plano é o que mais se aproxima do Planejamento Estratégico. Como afirmam Mintzberg et al. (2003, p. 39), é o

[...] plano que integra as principais metas, políticas e sequências de ação da organização em um todo coeso. Uma estratégia bem formulada ajuda a organizar e alocar os recursos de uma organização em uma postura única e viável, baseada em suas competências e deficiências internas relativas, mudanças antecipadas no ambiente e movimentos contingentes por parte dos oponentes inteligentes.

Indo em direção às crenças de que a estratégia pode se desenhar em diferentes contextos em que se encontram as firmas, Whittington (2002) propõe o agrupamento do comportamento estratégico em quatro quadrantes ortogonais como paradigmas. A abordagem clássica, em que classifica as estratégias como processo formal de análises deliberadas com aplicação de técnicas adequadas de planejamento; a evolucionista, sobrevivência do mais adaptado, que defende a ideia da seleção natural dos mais aptos, e, portanto, a maximização do lucro é condição necessária para sobrevivência das empresas em um ambiente de constante mutação, impossibilitando planejamento a longo prazo; a processualista: as estratégias se desenvolvem mais por processos emergentes que formais de aprendizado; e a sistêmica: as práticas de estratégia têm forte dependência do sistema social em que estão inseridas. Essas quatro abordagens estão distribuídas em dois eixos: o das abscissas aponta os processos deliberados e emergentes e o das ordenadas, os resultados financeiros ou múltiplos. Assim, apresenta que 
O eixo vertical (ordenadas) mede o grau em que a estratégia produz resultados de maximização dos lucros ou dele se desvia para permitir outras possibilidades. O eixo horizontal (abscissas) considera os processos, refletindo sobre em que medida a estratégia é produto de cálculos deliberados ou emerge por acidente (WHITTINGTON, 2002, p. 2).

Existem vários autores que defendem a abordagem clássica da estratégia, como, por exemplo, Ansoff e McDonnell (1993) e Porter (1989). Entretanto, também existem aqueles que defendem a estratégia como prática, como Whittington (1996) e Mariotto (2003).

Existem, também, outras correntes teóricas, com ênfases diferentes para explicar o comportamento estratégico das firmas na busca de desempenho superior, como propõem Hitt, Ireland e Hoskisson (2003) ao advogar a favor da adoção de estratégias genéricas das firmas na lógica da economia industrial, como posicionamento para alcançar desempenho superior. São posições cognitivas de articular, seja na lógica inside out (articulações do Resources Based View) ou outside in (articulações da economia industrial). Uma foca na direção em que se deve atender aos fatores externos à organização e a outra, os fatores internos, recursos e competências para se obter resultados superiores. A primeira é o pilar da Teoria da Visão Baseada em Recursos (o termo original é Resource Based View (RBV)), estudada por autores como Barney (1991) e Wernefelt (1984). Para Wernefelt (1984), as estratégias para alcançar desempenho superior devem ser suportadas pelos recursos da firma, tangíveis ou intangíveis, em vez de serem pautadas em seus produtos. Barney (1991) complementa mencionando que as fontes de vantagens competitivas sustentáveis são pautadas em recursos internos que sejam valiosos, raros, difíceis de imitar ou não substituíveis.

Estudando as convergências dos vários conceitos sobre estratégia, Nicolau (2001, p. 3) afirma que todos abordam a "inseparabilidade entre a organização e o meio envolvente, [...] a importância das decisões estratégicas para o futuro das organizações [...] e que todas organizações têm subjacente ao seu comportamento uma estratégia implícita ou explícita."

De Wit e Meyer (2010) abordam a estratégia fracionada e orientada por três dimensões: processo, conteúdo e contexto. O processo - como a estratégia é elaborada, analisada, implementada e controlada - é a dimensão que aborda quem está envolvido na formulação das estratégias e quando elas surgem; o conteúdo significa identificar o que a estratégia representa para a instituição; e o contexto analisa sob quais circunstâncias a estratégia é determinada.

Porter (1989) introduziu o conceito de estratégia competitiva na forma de barreiras que uma organização deve conhecer e com as quais deve trabalhar para obter vantagens, vis-à-vis seus concorrentes, para ser lucrativa, sustentável, mais duradoura no mercado, apresentar resiliência e atender à dinâmica dos mercados. De uma forma bem redutora, apresentou a ideia de vantagem competitiva como o "valor que uma empresa consegue criar para seus compradores e que ultrapassa o custo de fabricação pela empresa" (PORTER, 1989, p. 2). No quesito posicionamento, Porter (1989) propõe três estratégias genéricas para alcançar desempenho superior: (i) liderança de custo, que é repassado aos consumidores; (ii) diferenciação, para marcar posição no trade off qualidade versus custos e marcar a mente dos clientes; e (iii) escopo do enfoque, que remete ao tamanho e à especialização do segmento a concentrar os produtos, exigindo maior especialidade. Em continuação, contratado para estudar por que uns países se posicionam melhor que outros, Porter (1989) propõe o Modelo Diamante para explicar as diferenças. Nesse modelo, propõe quatro fatores que têm significativa influência no processo de inovação e aprimoramento das vantagens competitivas nas nações: (i) a estratégia da firma, estrutura e rivalidade, sendo que competição e cooperação são vitais para a sobrevivência das empresas; (ii) condições dos fatores de produção (recursos humanos, tecnológicos e capital); 
(iii) condições da demanda crescente dos clientes; e (iv) indústrias relacionadas e de suporte no que tange aos benefícios gerados pela proximidade com a cadeia de suprimentos.

\section{PROCESSO DE FORMAÇÃO E IMPLEMENTAÇÃO DE ESTRATÉGIA}

O processo de formação de estratégias é uma combinação de fatores externos e internos da organização, que, segundo Nicolau (2001), pode ser racional e formal; pode ser um processo negociado; ou pode ser um processo em construção permanente, mencionando que

\footnotetext{
A concepção predominante na literatura entende a formação da estratégia como um processo que se desenvolve através de uma série de etapas seqüenciais, racionais e analíticas e envolve um conjunto de critérios objetivos baseados na racionalidade econômica para auxiliar os gestores na análise das alternativas estratégicas e tomada de decisão (NICOLAU, 2001, p. 9).
}

Diversos autores são favoráveis à ideia de que a formalização de um plano estratégico é um instrumento fundamental para uma gestão de sucesso, promovendo o desempenho superior (ANSOFF; McDONNELL, 1993; PORTER, 1989). Nesses escritos, defendem a ideia de que um plano formal é necessário para as organizações atingirem melhores resultados, através do direcionamento de esforços para o alcance dos objetivos comuns almejados por elas.

Quanto a tipologias de estratégia, Nicolau (2001) propõe também três diferentes ocorrências: planejadas x realizadas; implícitas x explícitas; deliberadas x emergentes. As estratégias que são traçadas em um plano muitas vezes não correspondem àquelas que foram possíveis de serem implementadas, pois o ambiente sofre mutações constantes, causando, assim, uma disparidade entre planejado e realizado. A explicitação das estratégias em planos formais nem sempre ocorre nas organizações; portanto, algumas empresas não deixam de ter atuação estratégica, porém esta é implícita. Em continuação, Mintzberg et al. (2003, p. 25) afirmam que "[...] podemos distinguir estratégias deliberadas nas quais as intenções que existiam previamente foram realizadas, das estratégias emergentes, nas quais os modelos se desenvolveram sem intenções, ou apesar delas". Existe uma linha de autores que defende a ideia de que a formulação da estratégia segue uma visão deliberada, afirmando que

\footnotetext{
Sob o ponto de vista normativo, a estratégia formal pode representar importante elemento de legitimação para um grupo de referência, para uma rede interorganizacional de um ramo, setor ou campo, até mesmo no nível societário como o Estado e a sociedade civil. (MACHADO-DA-SILVA; VIZEU, 2007, p. 4).
}

Entretanto, existe outra linha de pensamento, que defende a estratégia como um processo emergente, não planejado, "no sentido de uma linha de ação que só é percebida como estratégica pela organização à medida que ela vai se desenrolando ou até mesmo depois que já aconteceu." (MARIOTTO, 2003, p. 79). Isso entra em concordância com os argumentos de Whittington (1996), para quem a estratégia é vista como um prática cotidiana do convívio social de agentes em processo contínuo de formulação e implementação de ajustes de condutas e recursos. Afirma que é um processo laboral construtivista no tempo presente da ação, portanto sempre emergente. Os dirigentes fazem estratégia em ato contínuo, formulando estratégias baseadas no conhecimento adquirido em suas rotinas de trabalho. 
Em se tratando de estratégias emergentes e deliberadas, Mariotto (2003, p. 91) declara que "A maneira tradicional de desenvolver estratégia, com um processo periódico e formal de Planejamento Estratégico, já não é mais suficiente para lidar com a nova situação". Acrescenta ainda que a formação da estratégia deve ser um processo contínuo, ao afirmar que

as intencionadas estratégias correntes estarão sendo constantemente desafiadas por novas estratégias emergentes, que poderão acabar se tornando as novas estratégias intencionais ou então virem a ser acomodadas dentro da estratégia intencionada em curso (MARIOTTO, 2003, p. 81).

Complementarmente, Belmiro (2001) defende a ideia de que é necessário desenvolver o pensamento estratégico antes de se formular planos, envolvendo a criatividade e intuição de qualquer participante da organização. O pensamento estratégico diz respeito a entender as constantes mudanças e incertezas que pairam sobre a empresa. "Se o pensamento estratégico estiver enraizado, o planejamento poderá ser iniciado. Planejamento é a prática de sinergia. [...] Planejamento é a metodologia e práticas que criam estruturas para o cumprimento das ideias" (BELMIRO, 2001, p. 295).

\section{PLANEJAMENTO ESTRATÉGICO}

Como se sabe, ANSOFF (1977) é um dos pioneiros na teoria de planejamento estratégico como método efetivo de apoio à gestão na busca das Best Practices, do programar para fazer acontecer. Define Planejamento Estratégico como um processo contínuo e sistemático de formulação de estratégias que possibilita tomar decisões em bases sistemáticas, racionais, por meio de programas formais de execução, para que os resultados alcançados sejam comparados com o planejado em sistemático follow up, controle e ajustes. São crenças de que o futuro pode ser alcançado pelo presente em uma racionalidade "quase-total", com atitudes volitivas de definição do destino, e de que os demais players estarão congelados e inermes face às ações dos concorrentes.

A despeito das crenças em sua funcionalidade e das críticas sobre sua efetividade, o Planejamento Estratégico, segundo Meirelles (2003), é uma ferramenta da estratégia bastante utilizada pelas organizações como busca de integração e articulação das diversas áreas da empresa, orientando-as para objetivos comuns; é também uma forma de resposta às rápidas mudanças no ambiente. Sua aplicação se difundiu após a Segunda Guerra Mundial, sendo que, em 1966, cerca de $85 \%$ das grandes empresas privadas norte-americanas passaram a adotá-lo (PEREIRA, 2006).

As etapas do Planejamento Estratégico, segundo Hitt, Ireland e Hoskisson (2003) podem ser agrupadas em: (i) concepção estratégica: declaração de missão (a razão de ser da instituição) e visão de negócios (como a empresa pretender ser no futuro); (ii) gestão do conhecimento estratégico: diagnóstico estratégico externo e interno - levantamento das oportunidades, ameaças externas e forças e fraquezas internas - e construção de cenários; (iii) formulação estratégica através do sistema de Planejamento Estratégico: elaboração de ações por meio de planos operacionais (programas táticos) e definição dos objetivos, que devem seguir uma hierarquia de importância, prioridade ou urgência; e (iv) implementação da estratégia: questões de estrutura e controles organizacionais, governança corporativa e liderança estratégica. 
Esse processo de Planejamento Estratégico consiste, então, na elaboração de um documento formal onde estarão expressos a missão, visão, valores, objetivos e metas da organização: o plano estratégico. Trata-se, portanto, de estratégias deliberadas, pois seguirão o planejamento concebido, e as ações serão controladas tendo por base o plano.

Para Mintzberg (2006, p. 96), o sistema de planejamento é desenvolvido de cima para baixo, ou seja, é formulado pela alta administração e vai sendo detalhado à medida que desce a hierarquia:

\footnotetext{
O sistema de planejamento [...] começa com o Planejamento Estratégico, em que a organização avalia sistematicamente suas forças e fraquezas em termos das tendências ambientais e, depois, formula um conjunto de estratégias explícitas e integradas que pretende seguir no futuro. Essas estratégias são depois desenvolvidas em 'programas', isto é, em projetos específicos.
}

Ansoff e McDonnell (1993) afirmam que o estudo do Planejamento Estratégico foi evoluindo ao longo dos anos, passando do planejamento financeiro, cujo foco principal era o orçamento, ao planejamento de longo prazo, depois Planejamento Estratégico, até chegar em administração estratégica, somando novas abordagens. Meirelles (2003, p. 39) acrescenta que:

\footnotetext{
[...] enquanto o Planejamento Estratégico tradicional ocupava-se em alinhar os pontos fortes da empresa às oportunidades do ambiente e neutralizar pontos fracos e ameaças externas, essa nova abordagem enfocou a necessidade de intervenção nas competências e fraquezas organizacionais.
}

Quando se fala em planejamento, é preciso lembrar-se do controle, pois ambos devem caminhar juntos, já que o propósito deste é verificar se o padrão daquele foi alcançado devidamente Mintzberg (2006, p. 89) menciona que "não pode haver controle sem planejamento e os planos perdem sua influência sem controles de acompanhamento."

\section{PLANEJAMENTO ESTRATÉGICO NO SETOR PÚBLICO}

Pela ausência de competitividade nos monopólios estatais e de outras formas de se mensurar desempenho, a percepção e o senso de utilidade de adoção do Planejamento Estratégico, como usualmente aplicado em ambientes competitivos, podem ser diferentes. Nesse sentido, a utilização de Planejamento Estratégico (PE) no setor público é mais recente que na esfera privada, e, nos últimos anos, seu uso vem crescendo gradualmente (PEREIRA, 2006). Para exemplificar: o Tribunal de Contas da União implantou o Planejamento Estratégico em 1994 (TCU, 2011); o Instituto Nacional de Metrologia, Normalização e Qualidade Industrial (Inmetro) em 1998 (GODINHO, 2005); a implantação em duas organizações militares prestadoras de serviço ocorreu em 1999 e 2001 (PEREIRA, 2006); e o Ministério da Agricultura, Pecuária e Abastecimento (Mapa) instituiu o primeiro PE em 2006 (FRESNEDA, 2011).

Apesar de existirem certas limitações na aplicação do Planejamento Estratégico em órgãos públicos (visto que o foco não é lucro nem busca de vantagens competitivas, uma vez que não existe a concorrência na forma como é verificada na esfera privada), este tema tem sido muito difundido nos últimos tempos, pois a excelência na prestação dos serviços ao cidadão passou a ser priorizada. A parte introdutória do plano estratégico 2009-2013 do Tribunal de Contas do Estado do Rio Grande do Norte (2011) evidencia isso ao relatar que 
Percebendo a mudança de atitude dos cidadãos, que exigem cada vez mais resultados das instituições públicas, os Tribunais de Contas no Brasil procuram responder às novas necessidades através de uma reestruturação na forma de gerenciar a organização, buscando garantir a eficiência administrativa e a efetividade das ações de controle. (TCU, 2011).

Giacobbo (1997), pesquisando sobre a motivação de organizações públicas para implementação de Planejamento Estratégico, apontou como um dos motivos acabar com a descontinuidade administrativa gerada pela troca da administração. Em vários órgãos públicos, essa troca ocorre de dois em dois anos, acarretando falta de continuidade nos projetos em andamento.

No governo do estado de Minas Gerais, a motivação para implementação do conhecido e aclamado Choque de Gestão, a partir do ano de 2003, foi a crítica situação fiscal em que se encontrava o estado (VILHENA et al., 2006). Esse modelo contempla uma abordagem dual de planejamento estratégico, envolvendo ações de curto e longo prazos.

Por se tratar de uma tema novo na esfera pública, o tema Planejamento Estratégico pode trazer certa resistência: um dos palestrantes do $2^{\circ}$ Fórum Nacional de Gestão Estratégica no setor público, tratando do início da implantação de Planejamento Estratégico em sua instituição no ano de 2009, disse que era visto como absurdo abordar esse tema, pois a visão do servidor público era de que estratégia não se aplica para instituições que não visam lucro.

Um fator que está presente em muitas instituições públicas e que dificulta a implementação do Planejamento Estratégico é a burocracia, cujas características fortes são: impessoalidade nas relações, divisão de responsabilidade, hierarquia formal, dificuldade de demissão, resistência a mudanças etc. (PEREIRA, 2006). No modelo burocrático, que Weber (1994) estudou profundamente, a criatividade não é estimulada. Trata-se de um modelo rígido, em que os funcionários se acostumam com uma visão departamentalizada de suas tarefas, não despertando a visão holística da organização.

Giacobbo (1997) também cita como características que estão presentes nas instituições públicas e que dificultam a implementação do Planejamento Estratégico: fidelidade ao passado, modelo de gestão centralizado, lentidão no processo decisório, imobilismo, privilégios estabelecidos etc. $\mathrm{O}$ autor também afirma que, devido à estrutura complexa e ao rigor burocrático nessas instituições, "a formalização do processo de planejamento (cronograma, manuais, definição de responsabilidades) e dos planos é muito importante e requer cuidados especiais para não comprometer o próprio processo de planejamento" (GIACOBBO, 1997, p. 86). Pereira (2006, p. 23) constatou, em sua pesquisa sobre formulação do Planejamento Estratégico em dois órgãos da Marinha, que "em ambas as organizações a elaboração ficou a cargo de poucas pessoas"; isso "tornou o planejamento mais um item de burocracia diária dessas organizações do que um fator motivador de mudanças".

Giacobbo (1997, p. 88) comenta as peculiaridades do tema afirmando que

o processo de desenvolvimento e implementação do Planejamento Estratégico em organizações públicas é bastante árduo e complexo, leva tempo e exige muita negociação, participação, barganha, habilidade e determinação na sua condução. Habilidade gerencial do administrador maior para fazer convergir os esforços, promover as mudanças e resolver os conflitos. Habilidade política e organizacional dos planejadores para conhecer e compreender as regras do jogo, fundamental para a viabilização da execução dos planos. Não basta aplicar as técnicas para resolver os problemas, é preciso efetivamente trabalhar as dimensões burocrática, política e comportamental presentes na organização. 


\section{CRÍTICAS AO PLANEJAMENTO ESTRATÉGICO}

Existem muitos críticos do Planejamento Estratégico que apontam para um sem fim de modelos desenvolvidos, mais assemelhados a modismos de consultores e editoras focados em vendas de serviços/livros. Micklethwait e Wooldridge (1998) acreditam que as várias perspectivas do Planejamento Estratégico não conduziram ao pensamento estratégico, pois distanciaram o pensamento da ação ao não dar ouvidos àquelas pessoas da organização que possuem contato mais próximo com o mercado. Os autores também afirmam que o Planejamento Estratégico perdeu o prestígio desde a década de 1980, pois se passou a dar menos crédito às previsões de futuro, já que, muitas vezes, estas falhavam. Micklethwait e Wooldridge (1998, p. 117) completam: "o que há exatamente de errado com a estratégia e o planejamento? A lista de acusações é grande, mas divide-se essencialmente em duas queixas: dificuldades práticas e impossibilidades teóricas."

Mintzberg (1994), discorrendo sobre a ascensão e queda do Planejamento Estratégico, aponta as falácias do mesmo: predeterminação, pois as organizações não têm condições de prever as mudanças no ambiente externo; desligamento, uma vez que não se pode separar o pensamento da ação, ou seja, os gerentes não devem se desligar dos processos operacionais; e formalização, que entendia o Planejamento Estratégico como formador de estratégias e não como auxiliar na formação das mesmas.

Existe também a questão da adoção cerimonial de práticas formais de estratégia, já que grande parte dos programas de Planejamento Estratégico não é efetivamente implementada: trata-se apenas de aparência (MACHADO-DA-SILVA, VIZEU, 2007).

Micklethwait e Wooldridge (1998) criticam as tentativas frustradas de levar os conceitos de administração de empresas privadas para o setor público sem adaptações necessárias à realidade deste setor. "De modo geral, entretanto, os casos de 'melhor prática' dentro do setor público são raros. Na maioria dos casos, o setor público simplesmente toma emprestadas as ideias do setor privado." (MICKLETHWAIT; WOOLDRIDGE, 1998, p. 252). Os autores também comentam que os gurus da administração não souberam criar novas ideias, que se adequassem ao setor público.

Percebe-se que existem opiniões favoráveis e contra a efetividade do Planejamento Estratégico como instrumento de apoio à gestão, porém elas devem ser cuidadosamente ponderadas. Críticas à parte, o Planejamento Estratégico continua sendo bastante utilizado pelas organizações, como exemplificou Pereira (2006, p. 1): "das 500 grandes empresas do mundo a maioria utiliza algum meio de Planejamento Estratégico, segundo a revista Fortune Global 500 de 2004".

\section{MODELOS DE PLANEJAMENTO ESTRATÉGICO COMUMENTE UTILI- ZADAS NO SETOR PÚBLICO}

Através de revisão bibliográfica realizada, apontou-se que várias instituições públicas iniciam o processo de formulação do Planejamento Estratégico usando as seguintes metodologias: Método Grumbach, Balanced Scorecard e Gerenciamento pelas Diretrizes. A seguir, serão apresentadas mais informações sobre cada modelo. 


\subsection{Método Grumbach}

O Método de Planejamento Estratégico com apoio de Cenários Prospectivos - Método Grumbach - foi desenvolvido por Raul Grumbach em 1996. O modelo é fundamentado em outras técnicas, como brainstorming, Método Delphi, Método de Impactos Cruzados, Teorema de Bayes, situação de Monte Carlo (análise da interdependência de variáveis e construção de diversos cenários), Teoria dos Jogos (análise de parcerias estratégicas) etc. Esse modelo foi usado por instituições como Banco do Brasil, Exército Brasileiro, Ministério Público do Estado da Bahia e de Goiás, Ministério Público do Trabalho, Polícia Federal etc. (GRUMBACH, 2000).

O método, segundo Grumbach (2000), contempla três elementos fundamentais - decisor estratégico, grupos de controle e peritos - e é composto por quatro fases, sendo as duas primeiras identificação do sistema e diagnóstico estratégico. A terceira fase, visão estratégica, se desdobra em visão do presente e do futuro, sendo que a primeira busca definir ações de curto e médio prazo baseadas no cenário atual e a segunda foca medidas de médio e longo prazo tendo em vista a geração e interpretação de cenários prospectivos. Nessa fase, primeiro são levantados e discutidos os eventos ou questões estratégicas que podem impactar a organização. A ocorrência ou não dos eventos resulta na quantidade de cenários possíveis, calculados por $2^{n}$, em que $n$ é o número de eventos. Os cenários são avaliados pelos peritos em relação à probabilidade de ocorrência dos eventos, ao impacto que estes causariam e à probabilidade condicionada de um evento em relação aos demais. Esta fase é realizada com auxílio do software Puma, em virtude da grande quantidade de cenários que podem ser gerados. Também é utilizado o software Lince, que auxilia no processo de Simulação e Construção de Futuro.

Ainda na fase 3, há a etapa de avaliação de medidas (que podem ser agrupadas em objetivos, política, metas) e gestão de resistência, buscando ações que aumentem a probabilidade de ocorrência de cenários favoráveis. Por fim, na quarta fase, Consolidação do Planejamento, são revisadas as informações obtidas nas fases anteriores e é elaborado o plano estratégico, que pode ser desdobrado em planos setoriais.

\subsection{Balanced Scorecard}

O Balanced Scorecard (BSC) é uma metodologia de gestão estratégica desenvolvida por Kaplan e Norton em princípios da década de 1990 para resolver problemas de monitoramento do desempenho das estratégias implantadas. No modelo geral, a análise da estratégia é agrupada em quatro grandes perspectivas abstracionais: financeira, clientes, processos de negócio interno e aprendizagem/crescimento, incluindo, assim, os ativos tangíveis e intangíveis. Kaplan e Norton (2001) descrevem quais temas são abordados em cada uma: (i) a perspectiva financeira engloba objetivos de crescimento, fontes de crescimento, produtividade, controle de custos etc.; (ii) a perspectiva clientes aborda o valor que a organização proporcionará aos mesmos para se diferenciar da concorrência, garantir fidelização e, assim, obter crescimento de receita; (iii) a perspectiva processos internos define as atividades da empresa que necessitam ser implementadas ou aprimoradas, para se garantir os objetivos de criação de valor aos clientes; (iv) a perspectiva aprendizagem e crescimento contempla qual infraestrutura, habilidades e conhecimentos dos empregados são necessários para uma atuação de forma inovadora e diferenciada.

A modelagem do BSC pode ser entendida como um painel mímico em que a alta direção corporativa pode se ater no comando da organização, consultando poucas variáveis agregadas e sem produzir excesso de informações para tomada de decisão. Em sentido estrito, é um 
modelo top down do Planejamento Estratégico.

A arquitetura original do BSC foi ajustada para aplicação às entidades governamentais, uma vez que a perspectiva financeira, originariamente no topo da hierarquia, não é prioritária para estas, podendo ser substituída pela perspectiva cidadão (KAPLAN; NORTON, 2001).

O modelo originalmente elaborado pelos autores foi sofrendo ajustes como a inclusão da mensuração no sistema gerencial, uma vez que a mensuração dos indicadores, além de mostrar o comportamento do passado, fornece subsídios para a atuação futura da organização. "Assim, refinamos o conceito do Balanced Scorecard e mostramos como seria possível convertê-lo de sistema de mensuração do desempenho em referencial organizacional do sistema gerencial estratégico." (KAPLAN; NORTON, 2001, p. 34). A figura 1 demonstra esse sistema.

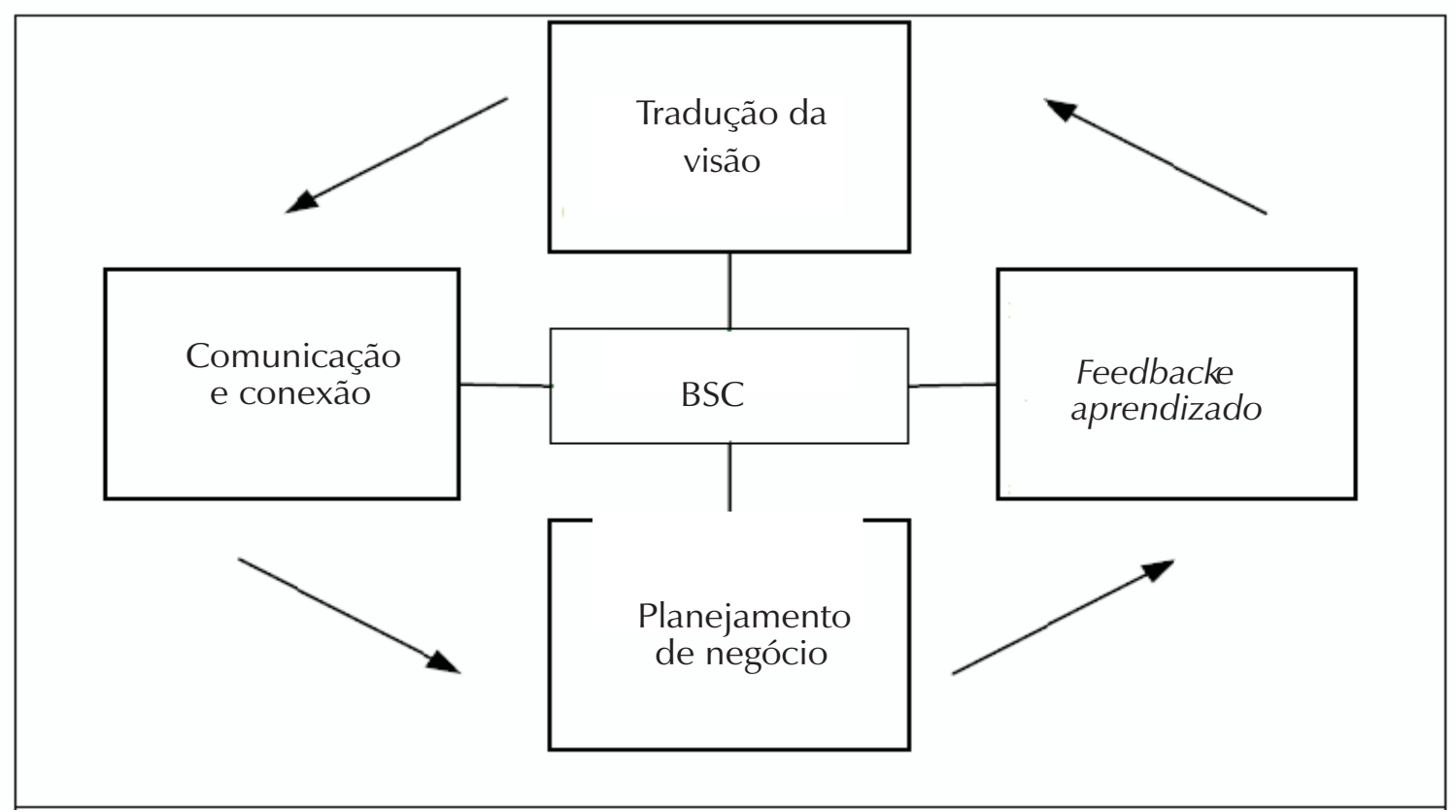

Figura 1 - Partindo de nova premissa.

Fonte: Kaplan e Norton (2001, p. 36).

Figura 1 - Partindo de nova premissa.

BSC

Planejamento de negócio

Feedback e aprendizado

Tradução da visão

Comunicação e conexão 
Os objetivos da organização são agrupados nas perspectivas e conectados por setas, que demonstram as relações de causa e efeito, elaborando, assim, um mapa estratégico. "O mapa estratégico do Balanced Scorecard explicita a hipótese da estratégia. Cada indicador do Balanced Scorecard se converte em parte integrante de uma cadeia lógica de causa e efeito, que conecta os resultados almejados da estratégia com os vetores que induzirão a essas consequências." (KAPLAN, NORTON, 2001, p. 81). Esse mapa facilita a comunicação da estratégia para toda empresa e o entendimento pelos funcionários de que os objetivos são interligados e impactam uns nos outros. Também permite, de forma fácil, a compreensão pelos colaboradores de como podem contribuir para execução da estratégia.

Várias são as instituições públicas no mundo que utilizam o BSC, sendo a cidade de Charlotte (Estados Unidos) e o estado do Rio Grande do Sul, no Brasil, cases de sucesso apresentados por Kaplan (2011). Outros exemplos no Brasil são: Embrapa (GALAS; FORTE, 2004), Inmetro (GODINHO, 2005), Ministério da Agricultura, Pecuária e Abastecimento (FRESNEDA, 2011) e Tribunal de Contas da União (2008).

\subsection{Gerenciamento pelas diretrizes}

Outro modelo de implementação do Planejamento Estratégico também utilizado no setor público, em instituições como o Tribunal de Justiça de Minas Gerais e a Empresa de Assistência Técnica e Extensão Rural do Estado de Minas Gerais (EMATER-MG) (2011), é a metodologia Gerenciamento pelas Diretrizes (GPD), que Campos (2004, p. 32) define como

\footnotetext{
Uma atividade voltada para solucionar os problemas relativos aos temas prioritários da organização [...]; é um sistema de gestão que conduz o estabelecimento e a execução do Plano Anual. As metas anuais da empresa são o ponto de partida concreto do Gerenciamento pelas diretrizes
}

Gerenciamento pelas diretrizes é uma tradução largamente utilizada para a expressão original Hoshin Kanri, que surgiu no Japão, por volta de 1960, como resultado da prática de empresas japonesas ganhadoras do prêmio Deming de qualidade (gerenciamento pela qualidade total ou Total Quality Management (TQM)).

O método de gerenciamento do GPD é o ciclo PDCA (em inglês, Plan-Do-Check-Act), que aborda o planejamento (estabelecimento das diretrizes e metas), execução dos planos de ação, monitoramento dos resultados alcançados e análise dos desvios entre estes e as metas propostas. Dessa forma, são determinadas as causas e medidas a serem tomadas.

Segundo Campos (2002), o GDP só mostrará eficiência completa quando o gerenciamento da rotina do dia a dia estiver bem entendido e for amplamente praticado, uma vez que este é a base do trabalho das organizações. Dentro desse gerenciamento, é defendida a exibição em quadros Gestão à vista do monitoramento dos indicadores, de forma que os resultados atingidos pelos departamentos são exibidos para toda a organização (CAMPOS, 2004). O gerenciamento pelas diretrizes e o gerenciamento da rotina são conduzidos simultaneamente e se relacionam através de padronização.

Para Campos (2002), o Planejamento Estratégico consta de três níveis: Plano de Longo Prazo, que pode durar de cinco a dez anos, em que são traçadas as estratégias para atingir a visão de futuro; Plano de Médio Prazo - três anos -, em que são definidas as metas sobre as estratégias dos planos de longo prazo; e Plano Anual, que contém o detalhamento dos planos de 
longo e médio prazos para o período de um ano. Este último deve detalhar metas concretas, que serão atingidas através de planos de ação $(5 \mathrm{~W} 1 \mathrm{H})$.

Campos (2002, p. 56) também discorre sobre o desdobramento de diretrizes: "Desdobrar uma diretriz significa dividi-la em várias outras diretrizes sob responsabilidade de outras pessoas. Cada diretriz estabelecida no desdobramento está intimamente ligada à diretriz original, num relacionamento meio-fim.". O autor também descreve os dois métodos de desdobramento de diretrizes: no método A, para cada meta, são estabelecidas medidas prioritárias e destas são estabelecidas novas metas para os níveis hierárquicos inferiores; no método B, o desdobramento ocorre em todos os níveis, para depois serem estabelecidas medidas em cada nível.

Constatou-se que o GPD também pode ser aplicado em conjunto com o BSC, de forma complementar, como exemplo do Tribunal de Contas da União (2008) e da Secretaria de Estado da Fazenda do Rio Grande do Sul (2011). O BSC é usado para formulação do plano de longo prazo e, complementarmente, o GPD atua no desdobramento de objetivos institucionais em individuais para todos os membros da organização no plano anual. Redi (2005, p. 63) estudou a combinação dos dois modelos e concluiu que "O balanced scorecard é um sistema poderoso para a explicitação, discussão e alinhamento da estratégia, enquanto o gerenciamento pelas diretrizes viabiliza a implantação dos programas escolhidos como estratégicos por toda a organização."

\section{METODOLOGIA DE PESQUISA}

Para verificar como ocorre o processo de formação e implementação do Planejamento Estratégico em instituições do setor público, a pesquisa foi estruturada em três etapas: (i) pesquisa documental de informações contidas nos planos estratégicos dos tribunais de contas do Brasil, disponíveis nos websites desses; (ii) aplicação de questionário estruturado; e (iii) entrevista com representantes dos departamentos de Planejamento Estratégico.

Trata-se, portanto, de uma pesquisa descritiva, quali-quantitativa. As unidades de análise são os processos de formação e implementação do Planejamento Estratégico nos tribunais de contas dos estados e municípios do Brasil na percepção da assessoria/diretoria de Planejamento Estratégico destes órgãos.

Foi aplicado um questionário de 15 itens, baseado na versão desenvolvida por Meirelles (2003), aos 28 tribunais de contas dos estados e municípios do Brasil participantes do Programa de Modernização do Sistema de Controle Externo dos estados, Distrito Federal e municípios brasileiros (Promoex). Dessa forma, a amostragem da pesquisa é não probabilística intencional, pois, segundo Lakatos e Marconi (2010), há interesse em obter informações de um determinado grupo. Nesta pesquisa, não há que se falar em aplicação de fórmulas estatísticas para cálculos de erro de amostra, como também não se pode generalizar os resultados, pois sua validade está limitada a um contexto específico.

O questionário foi estruturado da seguinte forma: 13 afirmações utilizando escala do tipo Likert de 5 pontos (com as âncoras de 1- Discordo totalmente a 5- Concordo totalmente); uma questão aberta sobre o ano em que foi implantado o primeiro plano estratégico; e uma questão sobre o fator motivador da adoção do Planejamento Estratégico.

Apenas dez tribunais responderam ao questionário. A entrevista livre foi dirigida a esses respondentes, e o foco foi verificar se, em uma avaliação geral, o Planejamento Estratégico havia obtido êxito e quais foram as dificuldades encontradas durante a formulação e implementação do plano. A identidade dos entrevistados será preservada, conforme acordado. 


\section{RESULTADOS DA PESQUISA}

A primeira fase da pesquisa foi a consulta aos 19 planos estratégicos dos tribunais de contas que se encontram disponíveis nos websites (os demais tribunais não disponibilizaram os planos na Internet). Verificou-se que o ciclo de planejamento gira em torno de 4 a 5 anos. Os planos, em geral, apresentam a metodologia usada, a concepção estratégica (missão, visão, valores e política da qualidade em alguns casos), a análise dos ambientes/cenários interno e externo (análise de SWOT), a definição das prioridades/objetivos estratégicos, as metas e indicadores (apenas cinco tribunais não apontaram indicadores no plano). A maioria dos planos (16) também apresenta o mapa estratégico na concepção do BSC.

A missão descrita por estes tribunais apresenta redação bem semelhante, já que são órgãos que têm a mesma função: exercer o controle externo em benefício da sociedade (com algumas variações). Uma similaridade na visão descrita pelos tribunais é que eles almejam ser reconhecidos pela sociedade pela atuação no controle externo: onze tribunais expressaram essa visão. Seis almejam ser instituições de referência no controle externo, e outras seis utilizam o termo "instituição de excelência" para expressar a visão de futuro. Os valores mais destacados pelos tribunais são ética, transparência, efetividade e comprometimento.

Quanto às perspectivas dos mapas estratégicos desses tribunais, em geral são contemplados: resultados, processos internos, pessoas e inovação (ou aprendizado e crescimento em alguns casos) e financeira (também escrita como orçamento e estrutura ou logística). A seguir, será apresentado o resultado da pesquisa quantitativa e das entrevistas.

Em relação à amostra estudada, todos os tribunais implantaram um plano estratégico após o ano de 2001, sendo que um deles está em fase de formulação do primeiro plano. Um fato interessante a ressaltar é que a metade dos pesquisados foi impulsionada a implantar o Planejamento Estratégico pelo Promoex. Esse programa teve início em 2006 e objetiva "a modernização do conjunto de Tribunais de Contas que atuam nos estados, Distrito Federal e Municípios, principalmente através da capacitação de pessoal, introdução de novos procedimentos e sistemas organizacionais e investimentos em informática." (PORTAL DOS TRIBUNAIS DE CONTAS DO BRASIL, 2011). Inicialmente composto por 32 dos 33 tribunais de contas do Brasil, o Promoex, em 2011, é composto por 28 deles.

A adoção da ferramenta Planejamento Estratégico é vista como ação de modernização, já que uma das metas do Promoex era que todos os participantes tivessem o Planejamento Estratégico criado e implementado até o final do programa (previsto inicialmente para 2009 e estendido para 2011). Essa meta está sendo alcançada no ano de 2011, sendo que os dois tribunais restantes estão implantando o primeiro ciclo de planejamento estratégico. Outro quesito importante a ser destacado é que, através do Promoex, foram criados o portal e a rede nacional dos tribunais de contas, com objetivo de cooperação e compartilhamento de experiências e melhores práticas, indo ao encontro da Teoria das Redes.

Verificou-se que o processo de formulação do plano estratégico, na maioria dos casos, conta com apoio de consultores externos, usa como referencial os planos de outras instituições e é um processo participativo: 90\% dos tribunais responderam que foram ouvidas sugestões dos diversos setores da instituição.

Pela figura 2, verifica-se que: sete tribunais contrataram consultoria externa para elaboração do primeiro plano estratégico (concordam total ou parcialmente); dois deles não contrataram mas contaram com apoio de outra instituição pública, como TCU; e apenas um não contou com auxílio de consultores. Cerca de 50\% continuaram a contratar consultorias para elaboração dos demais planos subsequentes. 


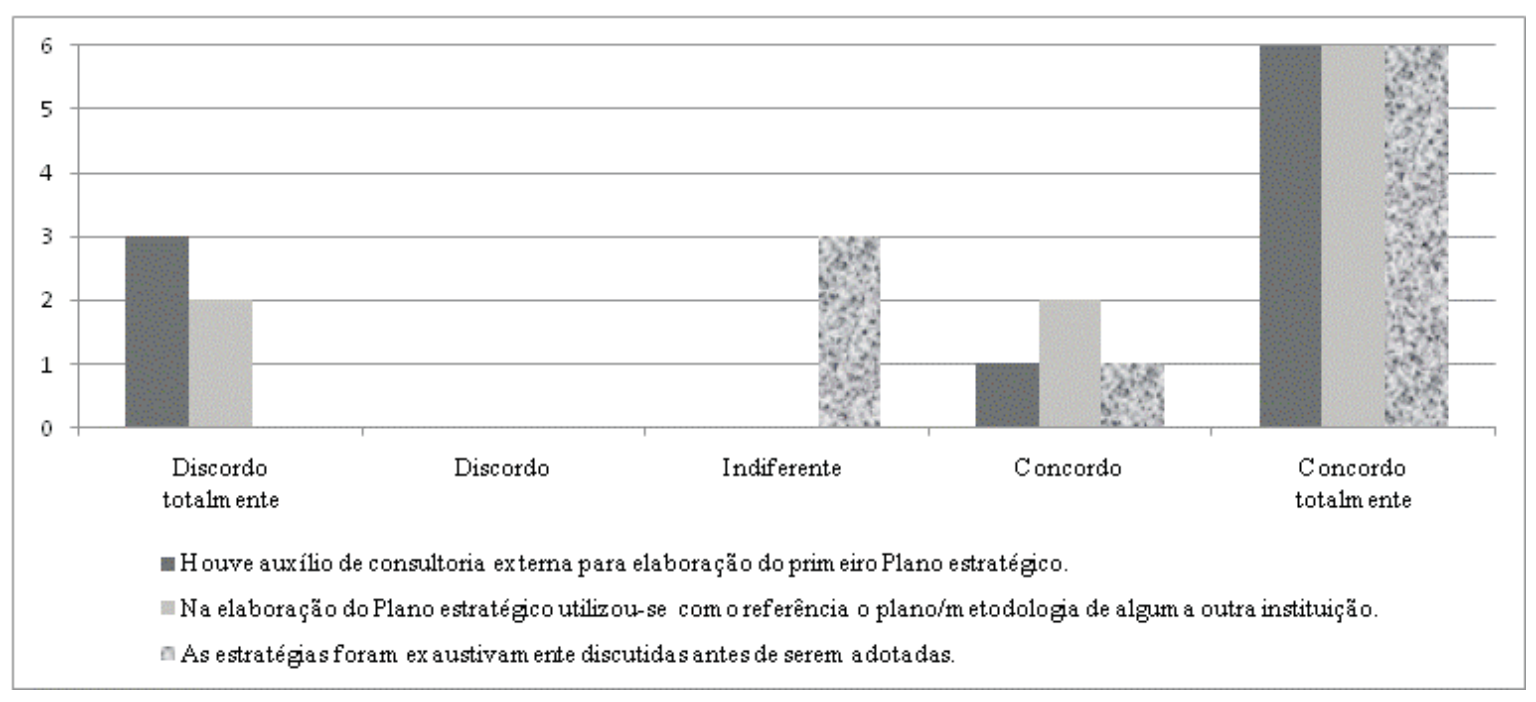

Figura 2 - Resultados da pesquisa relacionados à formulação estratégica Nota: dados trabalhados pelo autor.

Oito das instituições pesquisadas utilizaram como referência o plano de outros tribunais, sendo o TCU citado por três dos respondentes. Essa constatação remete a uma passagem de Whittington (2002), que afirmava que a importância da prática formal deve-se ao fato de que é concebida por grupos de referência. Também remete ao que Machado-da-Silva e Vizeu (2007, p. 2) explicam sobre o significado de isomorfismo mimético: "refere-se à imitação de arranjos estruturais e procedimentos levados a efeito com sucesso por outras organizações". Pela figura 2 , também se verifica que seis tribunais concordaram totalmente que as estratégias foram exaustivamente discutidas antes de serem adotadas.

Em relação à afirmação de que "a implementação do primeiro plano estratégico representou uma mudança inovadora nas práticas de gestão em relação ao que vinha sendo praticado até então", 50\% concordaram totalmente, um deles concordou, dois foram indiferentes, um discordou e um não tem condição de opinar ainda.

Os resultados da pesquisa mostraram que $90 \%$ dos tribunais utilizam metodologia Balanced Scorecard, sendo que, destes, $44 \%$ utilizam a metodologia híbrida com o modelo de Gerenciamento pelas Diretrizes. Nenhum dos tribunais pesquisados adotava monitoramento de resultados através de indicadores antes da adoção do Planejamento Estratégico.

Sobre o conhecimento e entendimento do plano pelos servidores públicos, 60\% dos tribunais responderam que concordam total ou parcialmente (os servidores conhecem o plano e entendem) e $40 \%$ discordaram total ou parcialmente. Porém, parece existir uma dificuldade do servidor público em relacionar seu trabalho com o alcance dos resultados do plano: três tribunais concordaram parcialmente que os servidores conseguem fazer essa relação, enquanto quatro discordam total ou parcialmente; três foram indiferentes à afirmação.

Quando abordados sobre o fato de haver distanciamento entre as estratégias formuladas e as que foram, de fato, implementadas (Figura 3), cinco tribunais discordaram ou discordaram totalmente (acreditam que as estratégias formuladas foram implementadas), um concordou e dois concordaram totalmente. Esse foi o item com maior divergência de respostas.

A maioria dos tribunais acredita que está sendo cumprida a agenda de acompanhamento e avaliação da implementação do Planejamento Estratégico (Figura 3): três concordaram e quatro concordaram totalmente com a sentença. A resposta "não aplicável" refere-se ao tribunal que está em fase de implantação, pois o mesmo não tem como avaliar essas questões. 


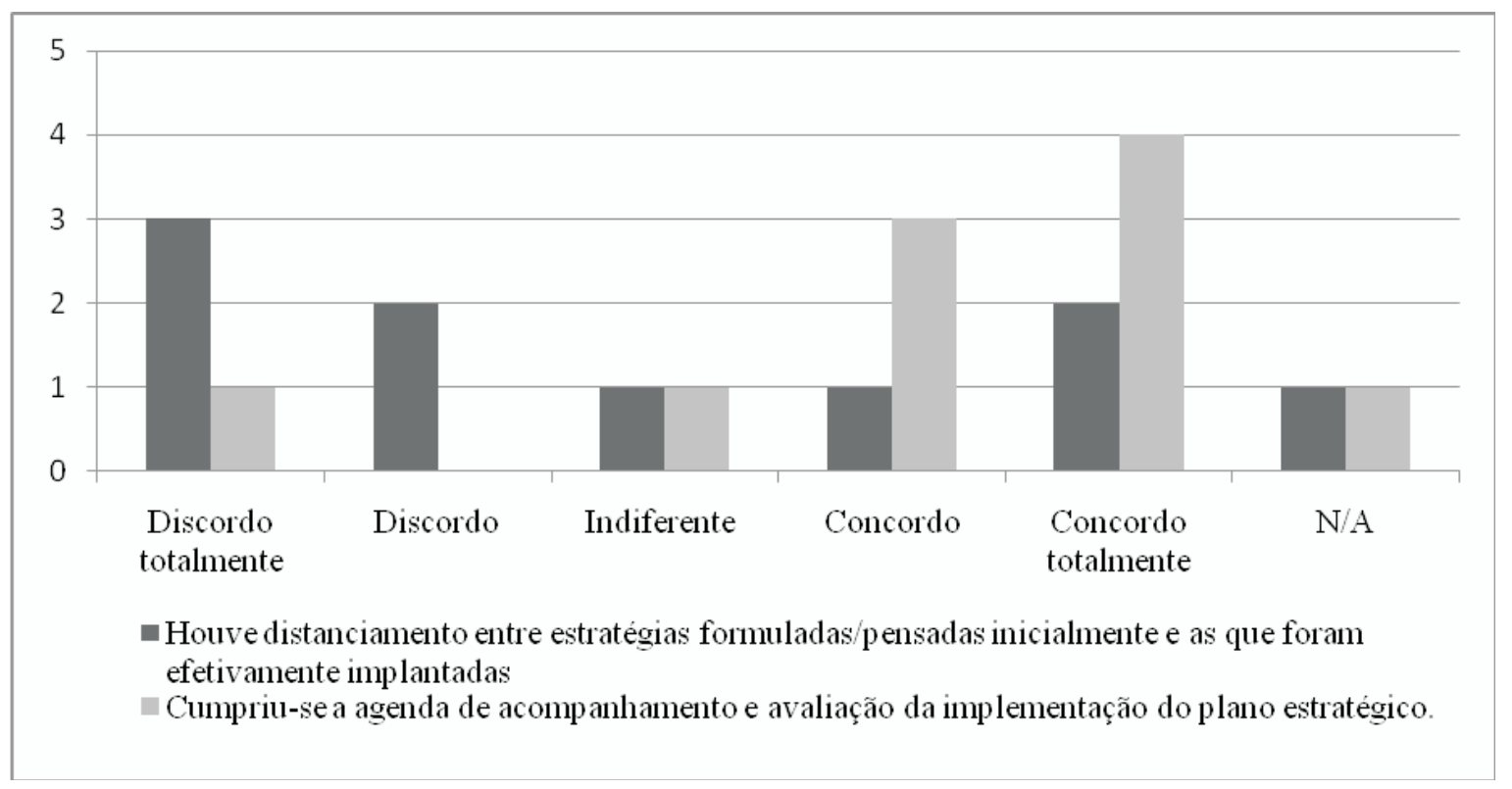

Figura 3 - Resultados da pesquisa relacionados à implementação Nota: dados trabalhados pelo autor.

Quanto à afirmação de que os resultados alcançados após institucionalização do plano estratégico foram muito melhores que os resultados apurados em programas/ações anteriores à institucionalização do plano, quatro tribunais concordaram totalmente, dois não responderam, dois não puderam opinar, pois estão em fase de implementação, e dois discordaram totalmente. Dada essa divergência de opinião, faz-se necessária uma pesquisa mais aprofundada sobre os resultados alcançados após implementação do Planejamento Estratégico, limitação desta pesquisa, pois o foco não foi analisar a efetividade dos resultados alcançados após adoção dessa ferramenta de gestão.

O resultado das entrevistas aponta que, na opinião dos integrantes da assessoria/diretoria de planejamento de alguns tribunais, a implementação do plano estratégico foi bem sucedida na medida em que possibilitou avanços não identificados em outras épocas nas instituições. "O plano possibilitou aos servidores públicos visão mais sistêmica da organização e identificação de sentido no trabalho desenvolvido, uma vez que estavam contribuindo para o alcance dos objetivos estratégicos" (Entrevistado 1). Entretanto, um dos respondentes considera que não houve sucesso na implementação do plano devido à falta de apoio da alta administração, afirmando que:

\footnotetext{
Muitas vezes, a administração priorizava ações de seu plano de gestão bienal (pois o plano estratégico pode ter sido formulado em outra gestão), deixando o plano estratégico de lado. Várias ações não foram cumpridas. O plano perdeu a credibilidade, pois a própria administração não estimulava o seu cumprimento. (Entrevistado 2).
}

Os entrevistados, em geral, ponderaram que o envolvimento da alta administração variou ao longo dos anos: algumas gestões foram mais engajadas e outras menos. Todos concordaram que a participação da administração é fundamental para dar força e credibilidade às ações do plano estratégico e que, quando essa participação não ocorre da maneira devida, o plano estratégico não é implementado no todo ou em parte. 
Um ponto de dificuldade encontrado por alguns tribunais ocorreu na fase de implementação do plano estratégico, pois alguns chegaram a formular o plano em anos anteriores, mas não conseguiram implementá-lo ou iniciaram a implementação, mas não conseguiram instituir procedimentos de monitoramento adequados. Esse ponto também foi levantado por Giacobbo (1997, p. 87) quando discorreu sobre motivos de fracassos na fase de implementação do plano estratégico "inexistência de sistemática de informações gerenciais, de indicadores e de avaliação de desempenho organizacional".

Outras dificuldades apontadas pelos entrevistados são: cultura da instituição avessa à mudança; falta de apoio da administração para divulgar e incentivar o plano; falta de envolvimento das pessoas-chave na execução das ações do plano; dificuldade em implementar metodologia de definição e medição de indicadores; dificuldade em desdobrar as ações do plano estratégico para as diversas unidades da organização; pressão dos servidores quanto ao fato de já terem uma rotina atribulada e ainda terem que dedicar tempo para o monitoramento das metas e indicadores referentes ao plano estratégico. Muitas dessas dificuldades são devidas à utilização do Planejamento Estratégico pela primeira vez. Com o passar dos anos, a experiência se acumula e algumas dessas dificuldades tendem a se reduzir.

\section{CONSIDERAÇÕES FINAIS}

As organizações públicas estão em busca da excelência na prestação de serviços e do reconhecimento pela sociedade de que são instituições eficientes e que cumprem seu papel. Para tanto, estão envidando esforços para implementar as melhores práticas de gestão.

Os defensores do Planejamento Estratégico apontam que suas vantagens estão em nortear as ações prioritárias da instituição, estabelecer prazos e metas e monitorar o desempenho através de indicadores. Além disso, a implementação de uma metodologia de Planejamento Estratégico, com definição e monitoramento de metas, desencadeia mudança na cultura organizacional, especialmente no setor público, pois a condição de estabilidade dos servidores e os planos de remuneração não geram muita motivação por desempenhos extraordinários.

Os críticos afirmam que qualquer tentativa de planejar tentando prever os acontecimentos futuros é inviável, e, desse modo, colocam em dúvida a validade de aplicação do Planejamento Estratégico como metodologia efetiva de previsão do futuro. Para eles, as estratégias são formuladas sem que sejam consultadas pessoas que detêm conhecimento valioso por estarem na linha de frente, levando ao fracasso a implementação dos planos.

O foco da pesquisa foi abordar como ocorre a formulação e implementação do planejamento estratégico. Percebeu-se que existem lacunas entre a fase de formulação e a fase de implementação, uma vez que, nesta última, foram identificadas as maiores dificuldades. No que tange ao conteúdo do plano estratégico, sua elaboração é feita de forma participativa, conta com apoio de consultorias e geralmente é embasada em planos estratégicos de outras instituições. As metodologias de gestão do Planejamento Estratégico geralmente utilizadas são o Método Grumbach, Gerenciamento pelas Diretrizes e Balanced Scorecard. Já no processo de colocar em ação as estratégias formuladas, surgem as maiores dificuldades, dentre elas: resistência à mudança; tomada de decisões distanciadas dos planos; falta de sistematização do processo de planejamento; e, muito destacadamente, falta de engajamento dos servidores e da alta administração para executar o planejamento. Quanto a este último ponto, Giacobbo (1997, p. 89) destaca que "O apoio e o compromisso da direção superior precisa ser explícito e corroborado pela prática diária. Comprometer-se apenas da boca para fora é garantia infalível de fracasso". 
Apesar de existirem opiniões favoráveis e contra o Planejamento Estratégico, especialmente quando se trata de setor público, a pesquisa mostrou que a crença em sua efetividade é grande. É possível que se perceba sentido de oportunidade de aprendizagem, verificação de pontos de metas e comprometimento de equipes ao longo do processo.

Pelo resultado da pesquisa, pode-se verificar que as instituições do setor público acreditam no Planejamento Estratégico como método para alcance de desempenhos superiores. Resta saber, mais detalhadamente, quais níveis de resultados superiores foram atingidos, tema como sugestão para nova pesquisa.

\section{REFERÊNCIAS BIBLIOGRÁFICAS}

ANSOFF, I. Estratégia empresarial. São Paul: McGraw-Hill, 1977.

ANSOFF, I.; McDONNELL, E. Implantando a administração estratégica. São Paulo: Atlas,1993.

BARNEY, J. B. Firm resources and sustained competitive advantage. Journal of Management. v. 17, n.1, p. 99-120, 1991.

BELMIRO, J. Estratégias emergentes. In: CAVALCANTI, M. Gestão estratégica de negócios: evolução, cenários, diagnóstico e ação. São Paulo: Pioneira, 2001.

CAMPOS, V. F. Gerenciamento da rotina do trabalho do dia-a-dia. 8. ed. Belo Horizonte: INDG Tecnologia e Serviços, 2004.

Gerenciamento pelas diretrizes. 3 . ed. Belo Horizonte: Editora de Desenvolvimento Gerencial, 2002.

DE WIT, B.; MEYER, R. Strategy: process, content, context: an international perspective. 4. Ed. London: McGraw Hill 2010.

EMPRESA de Assistência Técnica e Extensão Rural do estado de Minas Gerais. Sistema Integrado de Gestão. Disponível em: <http:// www.emater.mg.gov.br/doc/intranet/upload/

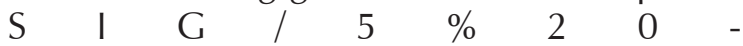
\%20gerenciamento\%20pelas\%20diretrizes.pdf>. Acesso em: 10 jun 2011.

FRESNEDA, P. A experiência do MAPA na execução da estratégia corporativa: foco nas pes- soas. In: FÓRUM NACIONAL DE PLANEJAMENTO ESTRATÉGICO NO SETOR PÚBLICO, 2., 2011, Brasília. Anais... Brasília, 2011. 1 CDROM.

GALAS, E. S.; FORTE, S. H. A. C. Fatores que interferem na implantação de um modelo de gestão estratégica baseado no Balanced scorecard: estudo de caso em uma instituição pública. Revista Eletrônica de Administração. Ed. 41, v. 10, n. 5, set./out. 2004.

GIACOBBO, M. O desafio da implementação do planejamento estratégico nas organizações públicas. Revista do TCU, Brasília, v. 28, n. 74, out./dez. 1997.

GODINHO, R. M. Implantação do Balanced scorecard no aprimoramento da gestão orçamentária do Inmetro. 2005. 88f. Dissertação. (Mestrado em Sistema de Gestão pela Qualidade Total) - Universidade Federal Fluminense, Niterói, 2005.

GRUMBACH, R. J. S. Prospectiva: a chave para o planejamento estratégico. 2 ed. Rio de Janeiro: Catau, 2000.

HITT, M. A.; IRELAND, R. D.; HOSKISSON, R. E. Administração estratégica. São Paulo: Bookman, 2003.

KAPLAN, R. S. NORTON, D. P. Organização orientada para a estratégia: como as empresas que adotam o balanced scorecard prosperam no novo ambiente de negócios. Rio de Janeiro: Elsevier, 2001.

Execução da estratégia no setor público com mapas estratégicos e Scorecards. In: FÓRUM NACIONAL DE PLANEJAMENTO ESTRATÉGICO NO SETOR PÚBLICO, 2., 2011, Brasília. Anais... Brasília, 2011. 1 CD-ROM. 
LAKATOS, E. M.; MARCONI, M. de A. Fundamentos de metodologia científica. 7 . ed. São Paulo: Atlas, 2010.

MACHADO-DA-SILVA, C. L. VIZEU, F. Análise institucional de práticas formais de estratégia. Revista Administração- eletrônica, p. 89100, out./dez. 2007.

MARIOTTO, F. L. Mobilizando estratégias emergentes, RAE, v. 43, n. 2, p.73-98, 2003.

MEIRELLES, A. de M. A formação de estratégia no sistema bancário brasileiro: modelo teórico e evidências empíricas. 2003. 414f. Tese (Doutorado em Administração)-Universidade Federal de Minas Gerais, Belo Horizonte, 2003.

MICKLETHWAIT, J.; WOOLDRIDGE, A. Os bruxos da administração. 8. ed. Rio de Janeiro: Elsevier, 1998.

MINTZBERG. H. Criando organizações eficazes. 2 ed. São Paulo: Atlas, 2006. Cap. 4.

The rise and fall of strategic planning: reconceiving roles for plannings, plans, planners. New York: Prentice Hall, 1994.

MINTZBERG et al. O processo da estratégia: conceitos, contexto e casos selecionados. Rio de Janeiro: Bookman, 2003.

NICOLAU, I. O conceito de estratégia. Lisboa: INDEG-ISCTE, 2001.

PEREIRA, S. C. de S. O planejamento estratégico em organizações públicas: um estudo de caso das organizações militares prestadoras de serviço. CONGRESO INTERNACIONAL DEL CLAD SOBRE LA REFORMA DEL ESTADO Y DE LA ADMINISTRACIÓN PÚBLICA, 11., 2006, Ciudad de Guatemala. Anais... Ciudad de Guatemala, nov. 2006.

PORTER, M. E. Vantagem competitiva: criando e sustentando um desempenho superior. 13. ed. Rio de Janeiro: Campus, 1989.

PORTAL dos tribunais de conta do Brasil. Promoex. 2011. Disponível em: <http:// www. controlepublico.org.br/ index.php? option $=$ com content\&view $=$ article\&id $=11$ \&ltemid $=17>$. Acesso em: 31 maio 2011.
REDI, R. Implementando a estratégia com apoio do balanced scorecard (BSC) e do gerenciamento pelas diretrizes (GPD). Revista Gestão \& Conhecimento, v. 3, n.1, p. 56-64, jan./jun. 2005.

SECRETARIA de Estado da Fazenda do Rio Grande do Sul. Modelo de Gestão. Disponível em: <http://www.sefaz.rs.gov.br/Site/ MontaDuvidas.aspx?al=I_a_secretaria $>$. Acesso em: 6 jun. 2011.

TCU. Tribunal de Contas da União. Guia de referência do sistema de planejamento e gestão, 2008.

TCU. Tribunal de Contas da União. Plano estratégico 1999. Disponível em:

<http://portal2.tcu.gov.br/portal/page/portal/ TCU/planejamento_gestao/planejamento/ planos_estrategicos_TCU/pet_1999.pdf $>$. Acesso em: 10 jun. $2 \overline{0} 11$.

TCU. Tribunal de Contas do Estado do Rio Grande do Norte. Plano estratégico 20092013. Disponível em: <http:// www.tce.rn.gov.br/2009/download/ Cartilha\%20TCE-28_10.pdf>. Acesso em: 10 jun. 2011.

TRIBUNAL de Justiça de Minas Gerais. Disponível em: <http://www.tjmg.jus.br/ institucional/at/pdf/po18932006.PDF>. Acesso em: 10 jun. 2011.

VILHENA, R. et al. O choque de gestão em Minas Gerais: políticas da gestão pública para o desenvolvimento. Belo Horizonte: Ed. da UFMG, 2006.

WEBER, M. Economia e sociedade: fundamentos da sociologia compreensiva. Tradução de Regis Barbosa e Karen Elsabe Barbosa. 3. ed. Brasília: Ed. da UnB, 1994.

WERNERFELT, B. A resource-based view of the firm. Strategic Management Journal, v. 5, n. 2, p. 171-180, 1984.

WHITTINGTON, R. Strategy as practice: long range planning, v. 29, n. 5. p. 731-735, 1996.

O que é estratégia. Tradução de Maria Lúcia G. L. Rosa e Martha Malvezzi Leal. São Paulo: Thompson, 2002. 